\title{
Water vapor permeation and dehumidification performance of poly (vinyl alcohol)/lithium chloride composite membranes
}

\author{
Duc Thuan Bui ${ }^{\mathrm{a}}$, Aqdas Nida ${ }^{\mathrm{a}}$, Kim Choon $\mathrm{Ng}^{\mathrm{b}}$, Kian Jon Chua ${ }^{\mathrm{a}, *}$ \\ ${ }^{a}$ National University of Singapore, Department of Mechanical Engineering, 9 Engineering Drive 1, Singapore 117576, Singapore \\ ${ }^{\mathrm{b}}$ Water Desalination \& Reuse Centre, King Abdullah University of Science \& Technology, Thuwal, Saudi Arabia
}

\section{A R T I C L E I N F O}

\section{Article history:}

Received 7 August 2015

Received in revised form

26 September 2015

Accepted 6 October 2015

Available online 9 October 2015

Keywords:

Air dehumidification

Water vapor permeance

Water sorption

Water diffusion

Activation energy

Vacuum membrane dehumidification

\begin{abstract}
A B S T R A C T
Thin and robust composite membranes comprising stainless steel scaffold, fine and porous $\mathrm{TiO}_{2}$ and polyvinyl alcohol/lithium chloride were fabricated and studied for air dehumidification application. Higher hydrophilicity, sorption and permeation were observed for membranes with increased lithium chloride content up to $50 \%$. The permeation and sorption properties of the membranes were investigated under different temperatures. The results provided a deeper insight into the membrane water vapor permeation process. It was specifically noted that lithium chloride significantly reduces water diffusion energy barrier, resulting in the change of permeation energy from positive to negative values. Higher water vapor permeance was observed for the membrane with higher $\mathrm{LiCl}$ content at lower temperature. The isothermal air dehumidification tests show that the membrane is suitable for dehumidifying air in high humid condition. Additionally, results also indicate a trade-off between the humidity ratio drop with the water vapor removal rate when varying air flowrate.
\end{abstract}

(c) 2015 Elsevier B.V. All rights reserved.

\section{Introduction}

The use of membranes for isothermal dehumidification processes has vast applications in a wide array of industries including heating, ventilation and air conditioning (HVAC) [1,2]; dehydration of flue gas [3-5], natural gas [6,7] and organic vapors [8,9]; drying of compressed air [10], steam recovery [9] and air treatment for packaging and processing industries.

Humid air or gas can be dried when it goes through the isothermal filtration setup [1,11-13] as shown in Fig. 1. In this setup, a permselective membrane is sandwiched between two chambers. One chamber is continuously fed with a stream of humid supply air. The other chamber is connected to a vacuuming system to produce a transmembrane pressure which acts as a driving force for the filtration process $[1,11,12,14]$. When the humid air stream passes along the membrane, the water vapor is selectively and efficiently sieved out. As a result, the air becomes dried without any change in its temperature [11-13,15].

The operation of the dehumidification system relies largely on the mechanical and permeation properties of the working membrane. Most of the membranes thus far have been constructed in a composite structure comprising support layers and an active layer $[6,13,14,16]$. The support layers provide the high mechanical

\footnotetext{
* Corresponding author.

E-mail address: mpeckje@nus.edu.sg (K.J. Chua).
}

strength and eventual chemical stability to the membrane. They are usually made of porous materials which have high permeability but no selectivity. The active layer is a thin permselective layer which determines the permeability and selectivity of the whole composite membrane. Composite membranes have higher permeability and mechanical strength than single-layer membranes with the same thickness. Therefore, the development of inexpensive and high performance composite membranes has attracted much research interest in the field of isothermal air/gas dehumidification $[1,6,12-14,16]$.

Thus far, hydrophilic polymer [1-3,6,8,12,17-19], ceramic materials [13] and liquid membranes [14,16,20-22] have been widely used for membrane active layer. Among them, hydrophilic polymer has attracted much attention due to its high water permeability and selectivity [2,4,6-8,12,17-19,23-26]. These are usually dense membranes for which water vapor transfer is based on solution-diffusion mechanism. Water molecules absorb on the membrane surface, diffuse through the membrane and then desorb at the opposite surface [25-27]. Transfer parameters such as permeance and selectivity are dictated by the membrane solubility and diffusivity properties. PVA polymer has been one of the popular choices of material for these membranes due to its hydrophilic properties, stability and ease of film formation $[2,8,12,19,23,24,28]$. The modification of PVA using lithium chloride to enhance water permeability has been reported $[12,19]$. The change of the polymer structure by including $\mathrm{LiCl}$ has been studied by means of FT-IR, XRD and thermal analysis [19,29]. $\mathrm{LiCl}$ salts disperse into the PVA matrix and 


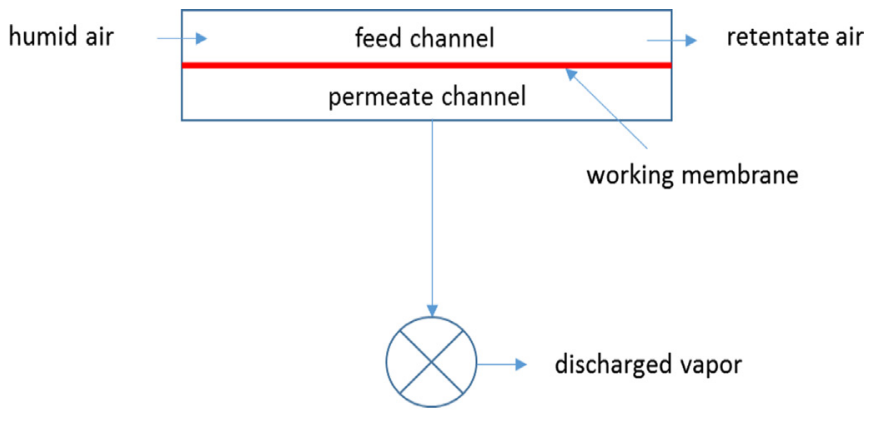

vacuum pump

Fig. 1. Dehumidification test setup.

weaken the hydrogen bonds between PVA chains. A complex formation was proposed between $\mathrm{LiCl}$ and PVA [29] with Li ions being the center cations and are weakly bonded with the oxygen atoms residing within the PVA molecules. As a result, the crystallinity of the PVA decreases with the higher $\mathrm{LiCl}$ contents. However, there are a lack of detailed research works on the analysis of the energies associated with water sorption and diffusion processes and how they affect the resultant water permeation. Therefore, the permeation mechanism of polymer membrane is still an area with a lot of potential for exploration.

Recently, we have developed an inexpensive, thin and highly stable metal-supported hydrophilic polyvinyl alcohol (PVA)/lithium chloride ( $\mathrm{LiCl}$ ) composite membranes using the dip-coating method [12]. In that study, experimental and modeling analyses were carried out to evaluate the performance of a vacuum membrane dehumidification system. In this study, the fundamental aspects of the water permeation, sorption, and diffusion energies are extensively studied to elucidate the role and influence of $\mathrm{LiCl}$ on the water transport phenomena in the membrane material. The study provides an in-depth understanding of the membrane permeation mechanism including the tailoring of the membrane properties for specific applications. The membranes were then tested in an isothermal filtration setup specially designed for air dehumidification.

\section{Experimental}

\subsection{Membrane preparation}

Anhydrous lithium chloride and polyvinyl alcohol (99\% hydrolyzed, molar weight of 85,000-124,000) were procured from Sigma Aldrich. Fine and porous $\mathrm{TiO}_{2}$ (Degussa P25) was obtained from Evonik Industries AG and used without further modification. Stainless steel mesh with twilled dutch weave and $5 \mu \mathrm{m}$ aperture was used as the scaffold.

A $5 \mathrm{w} \% \mathrm{TiO}_{2}$ suspension solution was prepared by adding P25 $\mathrm{TiO}_{2}$ to distilled water and subjected to vigorous stirring. PVA solutions were prepared by dissolving PVA in distilled water to form $5 \mathrm{w} \%$ solution under constant stirring at $90^{\circ} \mathrm{C}$. $\mathrm{LiCl}$ was then accordingly added to the PVA solution and stirred at room temperature for $2 \mathrm{~h}$ to obtain solutions with different PVA/LiCl mass ratios of $1: 0$ (PVA only), 5:1, 2:1, 3:2 and $1: 1$, corresponding to $0 \%$, $16.7 \%, 33.3 \%, 40 \%$ and $50 \% \mathrm{LiCl}$ content respectively.

The stainless steel scaffold was dip-coated in the $\mathrm{TiO}_{2}$ suspension solution and then dried at $80^{\circ} \mathrm{C}$ for $10 \mathrm{~min}$. The dipping and drying were repeated 10 times until an even white $\mathrm{TiO}_{2}$ layer covers all the mesh holes on both sides. The mass of the $\mathrm{TiO}_{2}$ layer was obtained to be $5 \mathrm{mg} / \mathrm{cm}^{2}$. The formed membranes were then dipcoated in the PVA/LiCl solutions and dried at $80^{\circ} \mathrm{C}$ for $10 \mathrm{~min}$.
Multiple layers were dipcoated and dried alternately to obtain a uniform selective layer with desired permeation properties. The mass of the polymer layer with 5 polymer dips was measured to be $5 \mathrm{mg} / \mathrm{cm}^{2}$.

\subsection{Membrane characterizations}

The membrane morphology was observed through the scanning electron microscope (SEM). The hydrophilicity of the membrane surface was tested by contact angle measurements using KINO SL150 with measuring accuracy of $\pm 0.1^{\circ}$. For each membrane, the contact angle reading was taken as the average of five equally spaced out points on the membrane.

The water vapor permeation properties of the membranes were estimated based on the cup method. The membrane with an area of $33 \mathrm{~cm}^{2}$ was mounted on the opening of a test cup. The test cup was fully filled with dried silica gel to minimize the resistance of still air gap between silica gel and membrane. The test cup was placed in a humidity and temperature chamber so that the humidity difference between the two sides of the membrane was precisely controlled. The air inside the chamber was vigorously circulated with a strong air displacement fan to minimize boundary layer resistance on the outer side of the membrane. The accuracies of temperature and relative humidity are $\pm 0.2^{\circ} \mathrm{C}$ and $\pm 1 \%$, respectively. Water vapor permeance $(P)$ was obtained from the weight increase of the test cup $[12,30]$. To study the effect of temperature, the water vapor permeations of the membranes were measured at different temperatures, assuming that the sorption property of silica gel was unchanged. From the obtained result, the water vapor permeation energy was determined.

Air permeance measurements were conducted according to the ISO 15105-1 standard. The membrane was mounted on a gas transmission cell so as to form a sealed barrier between two chambers. Both chambers were evacuated. Dry air was then introduced to one chamber and the pressure in the other chamber was monitored over time. The air permeation through the specimen was determined based on the pressure change [12]. Pressure measuring resolution of 1 mbar. It was reported that $\mathrm{N}_{2}$ permeability is independent of water content in feed gas $[3,17]$. Therefore, the water vapor selectivity toward air can be estimated by the ratio of water vapor permeance to air permeance.

Water vapor sorption of the mixtures of PVA and $\mathrm{LiCl}$ were studied using Quantachrome Aquadyne DVS gravimetric dynamic vapor sorption analyzer. The water sorption capacity $(C)$ is defined as

$C=\frac{m_{e}-m_{0}}{m_{0}} \cdot 100 \%$

where, $m_{e}$ and $m_{0}$ are masses of the sample at water absorption equilibrium and dry states, respectively. The effect of temperature on the sorption property of the material was studied, and then the sorption energy was determined. Gravimeter, relative humidity and temperature accuracies are $\pm 1 \mu \mathrm{g}, \quad< \pm 2 \%$ and $\pm 0.2^{\circ} \mathrm{C}$, respectively.

The dehumidification performance was tested in an instrumented experimental setup shown in Fig. 1. A flat sheet membrane with an area of $20 \mathrm{~cm}^{2}$ was mounted between the two chambers-feed and permeate channels. Geometry of both permeate and feed channels is $W 20 x L 100 x H 2.5 \mathrm{~mm}$ [12]. Permeate channel was connected to a vacuum pump. Permeate pressure was set at $1 \mathrm{mbar}$ and monitored by a pressure gauge (Omega DPG1000B, accuracy $< \pm 0.35 \%$ ). In the feed channel, an inlet humid air with relative humidity (RH) of $90 \%$ and humidity ratio of $17 \mathrm{~g}$ water vapor $/ 1 \mathrm{~kg}$ air was passed over the membranes at room temperature of $24^{\circ} \mathrm{C}$. The flow rate of the inlet air was controlled using a suction pump and a Kobold KFR2113NO flow meter with 
the measurement error of $0.05 \mathrm{~L} / \mathrm{min}$. Vaisala HMT338 humidity and temperature transmitters with temperature and relative humidity accuracies of $\pm 0.2{ }^{\circ} \mathrm{C}$ and $\pm 1 \%$ were placed at the inlet and outlet of the feed chamber to measure the change in the water vapor content of the feed air after it passes through the membrane test chamber. The dehumidification performance was calculated based on the humidity ratios at the inlet $\left(\omega_{\text {inlet }}\right)$ and outlet $\left(\omega_{\text {outlet }}\right)$ as follows:

Dehumidification performance $(\%)=\frac{\omega_{\text {inlet }}-\omega_{\text {outlet }}}{\omega_{\text {inlet }}} \times 100 \%$

A numerical model was developed for this membrane setup following our recent report [12]. There is a good agreement between experimental results and simulated data shown in Fig. 10.

\section{Results and discussion}

\subsection{Membrane characterization}

\subsubsection{Membrane morphology}

In order to design and fabricate a thin and robust membrane for isothermal dehumidification, which can resist deformation caused by high transmembrane pressure and other physical/chemical/biological corrosions, stainless steel wire mesh (Fig. 2(a)) is used as a scaffold for the membrane. Due to the weave structure of the mesh, there are micron-sized gaps between the wires. Hydrophilic $\mathrm{TiO}_{2}$ were coated as a low resistance intermediate layer to fill the gaps, as shown in Fig. 2(b). $\mathrm{TiO}_{2}$ powder is selected because it is an abundant, inexpensive, environmental friendly, chemically and physically stable material. It is also highly compatible with the polymer and the mesh. Additionally, it has negligible effect on the water vapor permeability and selectivity of the polymer layer.

A thin, smooth and free of defect layer of hydrophilic polymer was successfully coated on the $\mathrm{TiO}_{2}$ intermediate layer shown in Fig. 2(c). Cross-section of the composite membrane with 5 polymer dips is shown in Fig. 2(d). Both $\mathrm{TiO}_{2}$ and polymer cover fully both side of the wire mesh. From the cross-sectional SEM image, it is apparent that the $\mathrm{TiO}_{2}$ and polymer layers are indistinguishable. This suggests that a part of polymer has penetrated into the $\mathrm{TiO}_{2}$ layer. The total thickness of the membrane was measured to be $180 \mu \mathrm{m}$ while the thickness of the $\mathrm{TiO}_{2} /$ polymer composite layer on each side of the mesh was measured to be $23 \mu \mathrm{m}$. The synthesized membrane can withstand significant mechanical forces under varying operating conditions, such as transmembrane pressures up to 1 bar, with no physical damage detected. Because $\mathrm{LiCl}$ is a non-volatile compound, the leaching of $\mathrm{LiCl}$ is negligible and, therefore, the long-term stability of $\mathrm{LiCl}$ in the membrane is high.

\subsubsection{Water vapor permeation and selectivity}

Water vapor permeation and selectivity measurements of the individual membrane layers showed that the membrane selectivity is mainly derived from the top polymer layer. The water vapor permeance and water/air permeance ratio of the membranes with different number of polymer dips are shown in Fig. 3. As the number of polymer dips is increased, lower water vapor permeance and higher water selectivity is observed. The water permeance trend is reasonable since the thickness of the perm-selective layer increases with higher number of polymer dips. The effect of polymer dips is more prominent on selectivity, as the water/air permeance ratio increases by almost four orders of magnitude as the number of layers is increased from 1 to 7 , as
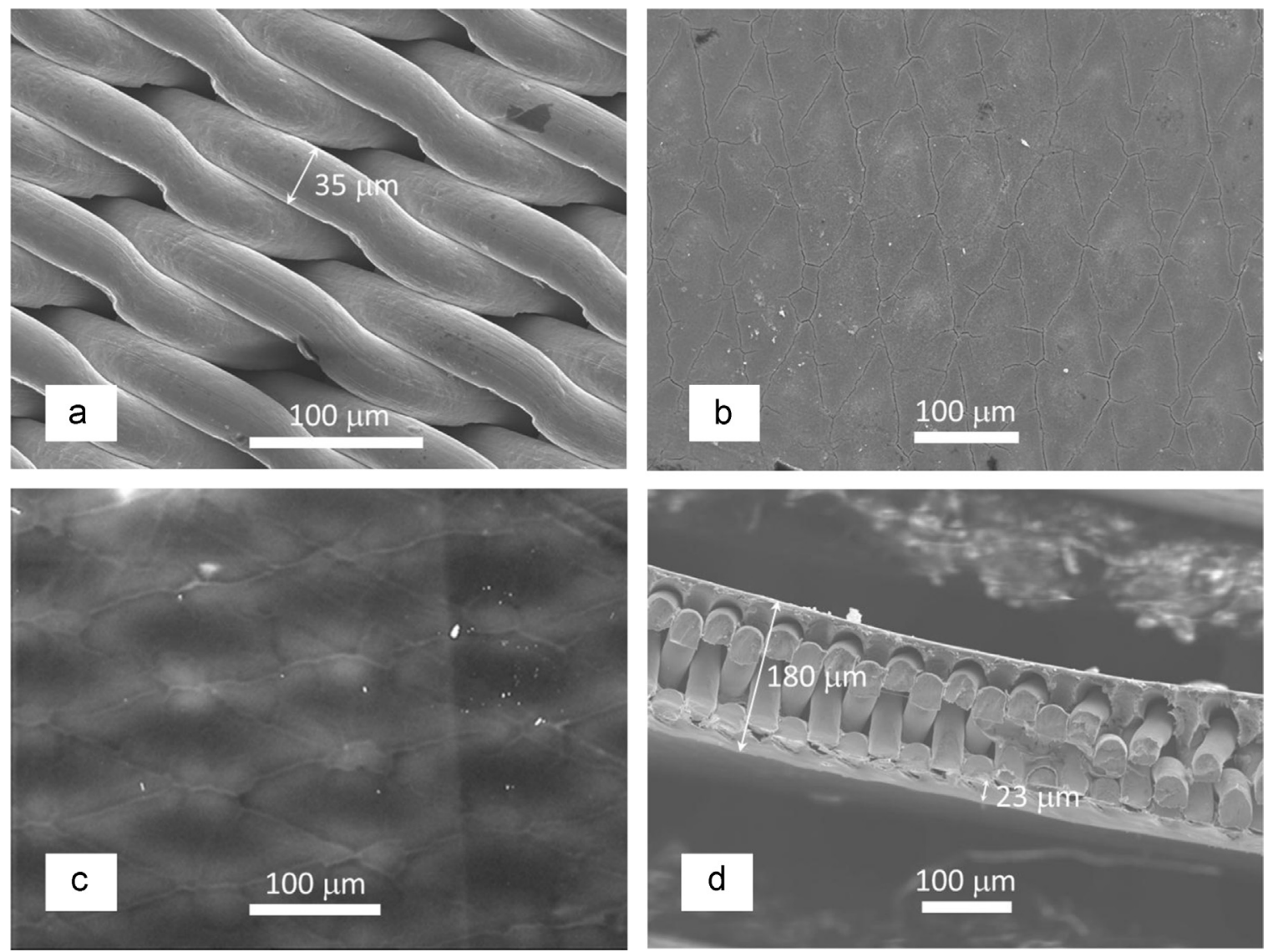

Fig. 2. SEM surface image of (a) wiremesh scaffold, (b) $\mathrm{TiO}_{2}$ layer, (c) top polymer layer and (d) membrane cross-section. The number of polymer dips was 5 . 


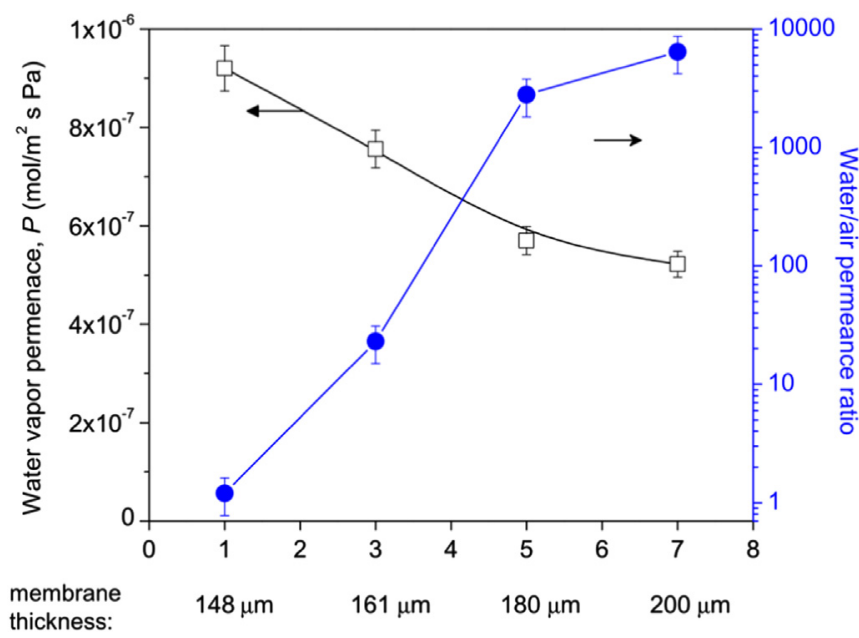

Polymer dips

Fig. 3. Water vapor permeance, water vapor permeance/air permeance ratio of the membranes and membrane thickness with different number of polymer dips and PVA: $\mathrm{LiCl}$ ratio of $3: 1$. The water vapor permeation tests were carried out at $70 \% \mathrm{RH}$ and $24{ }^{\circ} \mathrm{C}$. (2988 GPU $\left.=1 \cdot 10^{-6} \mathrm{~mol} /\left[\mathrm{m}^{2} \mathrm{~Pa} \mathrm{~s}\right]\right)$.

depicted in Fig. 3. Therefore, increasing the number of polymer drastically reduces non-selective pathways by covering any macrosurface defects of the membrane. Membranes with five dips have sufficiently high permeability (300,000 barrer) and selectivity (2800) for efficient use in dehumidification testing since the air permeation loss through the membrane becomes negligible.

\subsubsection{Membrane hydrophilicity}

The hydrophilicity of the membranes with varying content of lithium chloride was evaluated through their contact angles measured between the water drops and the membrane surface. The changing of contact angles due to varying $\mathrm{LiCl}$ content is shown in Fig. 4.

Adding of lithium chloride lowers the surface contact angle. This indicates an increase in hydrophilicity of the top polymeric layer. $\mathrm{LiCl}$, a strongly hygroscopic substance, when added to PVA increases the water vapor affinity of the polymer. This is one of the factors which benefits the membrane permeability. The other factor affecting the dehumidification performance is the water diffusivity through the bulk membrane material. The sorption

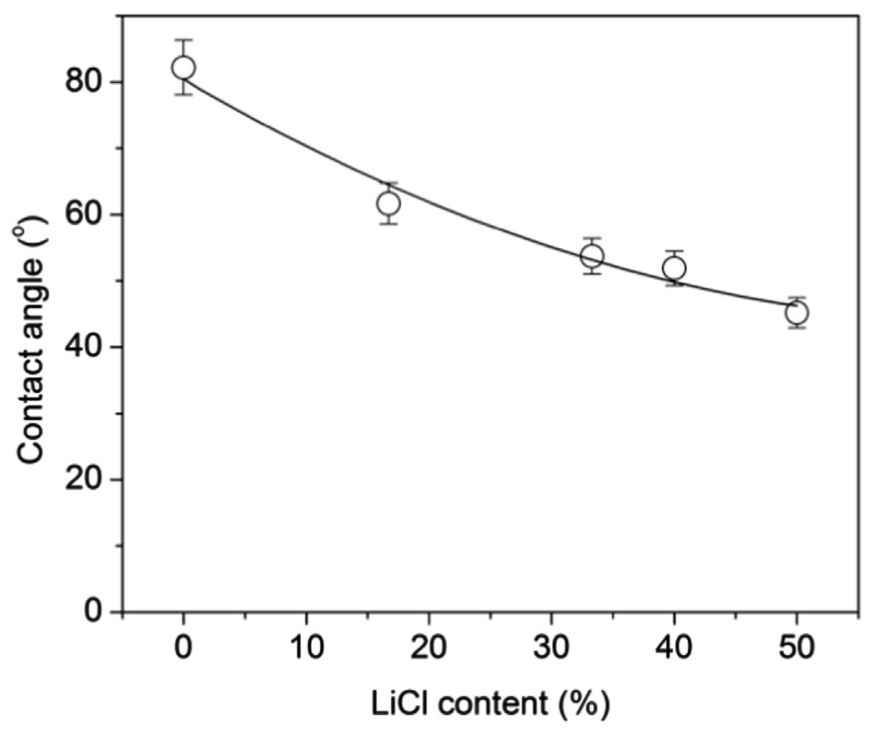

Fig. 4. Dependence of contact angle on $\mathrm{LiCl}$ content. property of the membrane is further studied in the next section.

\subsubsection{Water vapor permeation and sorption property}

The relative humidity of the feed air and $\mathrm{LiCl}$ content strongly influence the permeability and soprtion property of the membranes. The effect of relative humidity on the membrane's water vapor permeance and absorbability with different $\mathrm{LiCl}$ contents was investigated under a temperature of $24^{\circ} \mathrm{C}$. The membrane permeance increases with higher $\mathrm{RH}$ of the feed air and $\mathrm{LiCl}$ content, as can be seen in Fig. 5(a). Similar effect of RH has been observed for other polymeric membranes documented in literatures [3,30]. Similarly, the water sorption capacity, $C$, also increases with higher $\mathrm{RH}$ and $\mathrm{LiCl}$ content. It is apparent that the water vapor permeability is proportional to the water content in the polymer [31]. This is because adsorbed water disrupts the hydrogen bonding between the polymer chains, swells up the polymer, and increases the polymer chain mobility $[17,19]$, resulting in higher water diffusion rate. High water vapor permeance at high $\mathrm{RH}$ is advantageous for this membrane employed under humid condition. However, low water vapor permeance at low RH limits the use of this membrane to achieve low humidity of the product air.

\subsection{Thermodynamics of water vapor permeation, sorption and diffusion}

\subsubsection{Permeation energy}

The water vapor permeance $(P)$ through membranes with different $\mathrm{LiCl}$ contents for varying temperatures, with fixed relative humidity, is shown in Fig. 6(a). For temperatures ranging from 24 to $40^{\circ} \mathrm{C}$, considered the typical temperature in tropical climate, the water vapor permeance increases with higher content of $\mathrm{LiCl}$.

As far as temperature dependence is considered, the trends for the permeation changes are not the same for all the membranes. It gradually varies from going up to going down with higher temperature when the $\mathrm{LiCl}$ content is increased from 0 to $50 \%$. These results provide a deeper insight into the effect of adding $\mathrm{LiCl}$ on the membrane structure and to resulting transport properties. The temperature dependence of the membrane permeability is well described via the Arrhenius-van't Hoff equation [8]:

$P=P_{0} e^{-E_{P} / R T}$

where $E_{P}$ is the activation energy of water permeation for the membrane, $P$ is the permeability, $P_{o}$ is the pre-exponential factor, $R$ is the molar gas constant and $T$ is the temperature in Kelvin. The plots for the logarithm of water vapor permeance against the reciprocal temperature for the membranes containing different $\mathrm{LiCl}$ contents are displayed in Fig. 6(b). The permeation energies for the membranes are obtained from the line gradients, and are plotted in Fig. 7.

The computed permeation energies demonstrate the membranes' unique behavior with different $\mathrm{LiCl}$ contents. The pure PVA membrane has a high positive activation energy of permeation. With increasing $\mathrm{LiCl}$ content, the activation energy decreases and then becomes negative. This result supports the solution-diffusion mechanism, in which water dissolves in the membrane material and diffuses through the membrane down the pressure gradient. The water vapor permeation energy $\left(E_{p}\right)$, which is the summation of the water vapor sorption enthalpy $\left(E_{\mathrm{s}}\right)$ and water diffusion energy $\left(E_{d}\right)$, is provided as follows:

$E_{P}=E_{s}+E_{d}$

Since the water sorption of hygroscopic materials is an exothermic process, it is expected that $E_{s}$ is negative. Meanwhile, $E_{d}$ is positive because diffusion always increases with higher temperature. Therefore, the temperature dependency of the overall water 

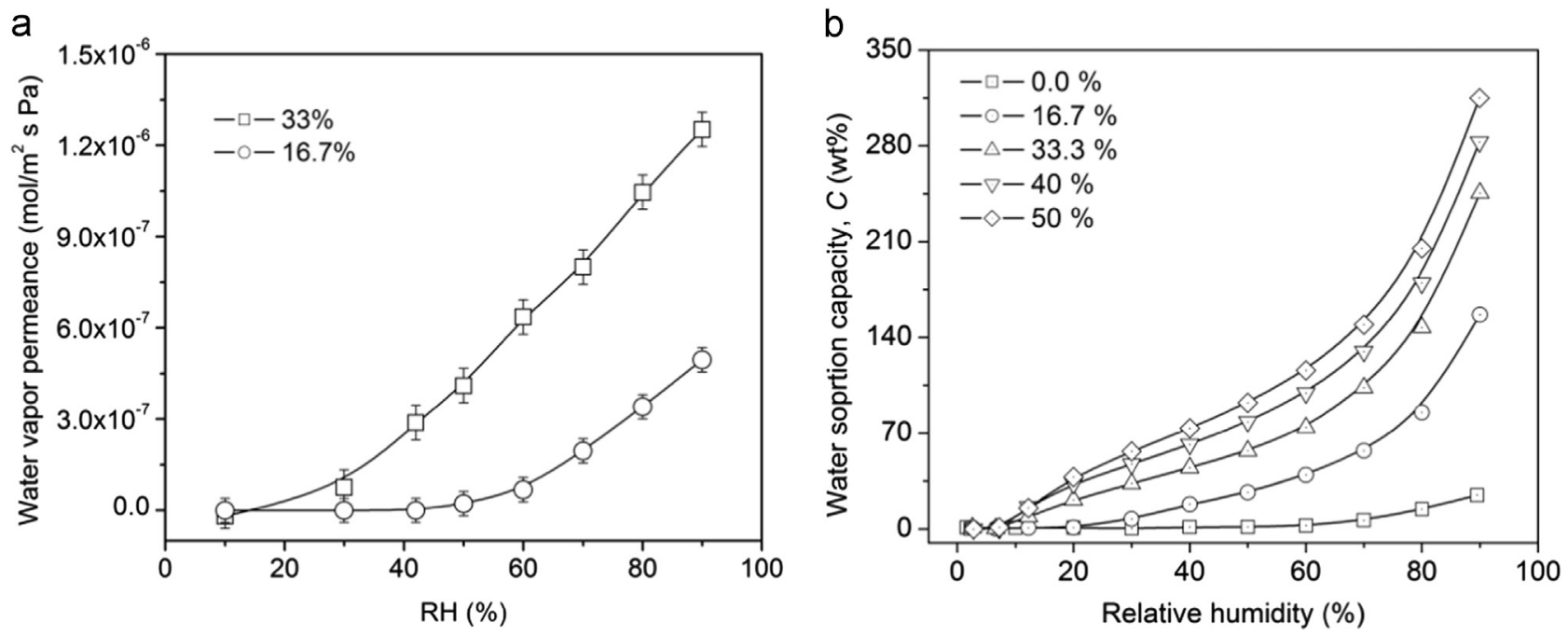

Fig. 5. The effects of $\mathrm{RH}$ and $\mathrm{LiCl}$ content on (a) water permeability and (b) water absorbability of the membrane at $24{ }^{\circ} \mathrm{C}$.

vapor permeation is the net result of two opposite effects of temperature on diffusion and sorption.

\subsubsection{Sorption and diffusion energies}

In order to determine the energy associated with the water vapor sorption process, $E_{s}$, the PVA/LiCl mixtures' isotherms were measured at different temperatures. The isotherms of $\mathrm{PVA} / \mathrm{LiCl}$ mixture with $40 \%$ of $\mathrm{LiCl}$ at different temperatures are shown in Fig. 8(a).

$E_{s}$ is calculated using the Clausius Clapeyron equation [32]:

$\ln \left(P_{w}\right)=-\frac{\Delta H_{s}}{R} \cdot \frac{1}{T}+C n t$

where $P_{w}$ is vapor pressure of water at equilibrium state, and $C n t$ is a constant.

Water sorption energy at different sorption capacities is obtained from the slope of the plots, $\ln \left(P_{w}\right)$ versus $1000 / T$, shown in Fig. 8(b). Every water sorption capacity value corresponds to one specific $\mathrm{RH}$ value in an isotherm at a certain temperature. Therefore, the dependence of the calculated sorption energy on $\mathrm{RH}$ for a membrane with $40 \%$ of $\mathrm{LiCl}$ at $30{ }^{\circ} \mathrm{C}$ is shown in Fig. 8(c). To compare the sorption energies with the permeation activation

a

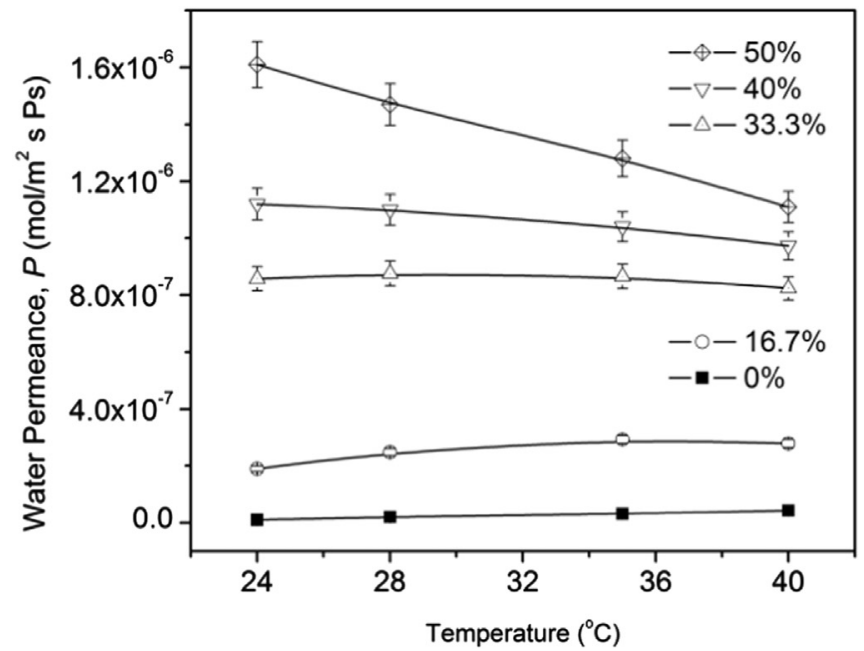

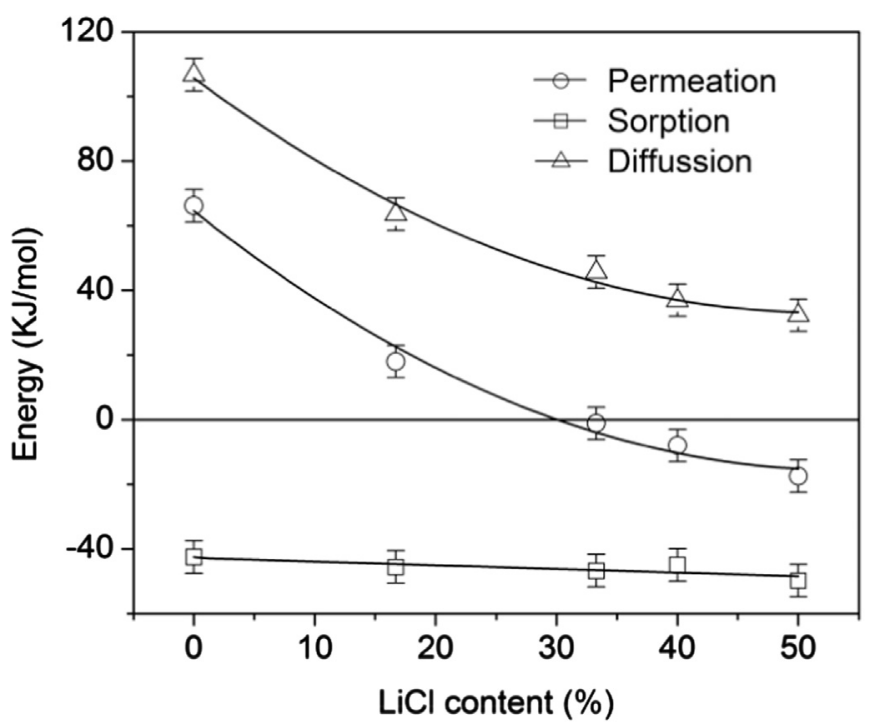

Fig. 7. Permeation, sorption and diffusion energies of the membranes with different $\mathrm{LiCl}$ contents.

b

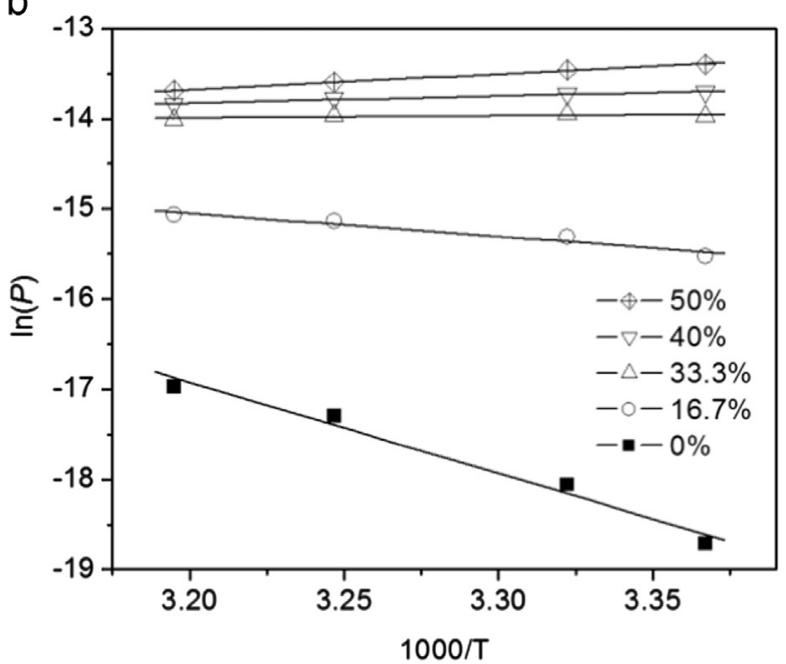

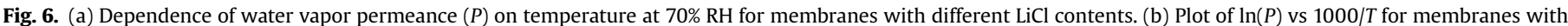
different $\mathrm{LiCl}$ content. 


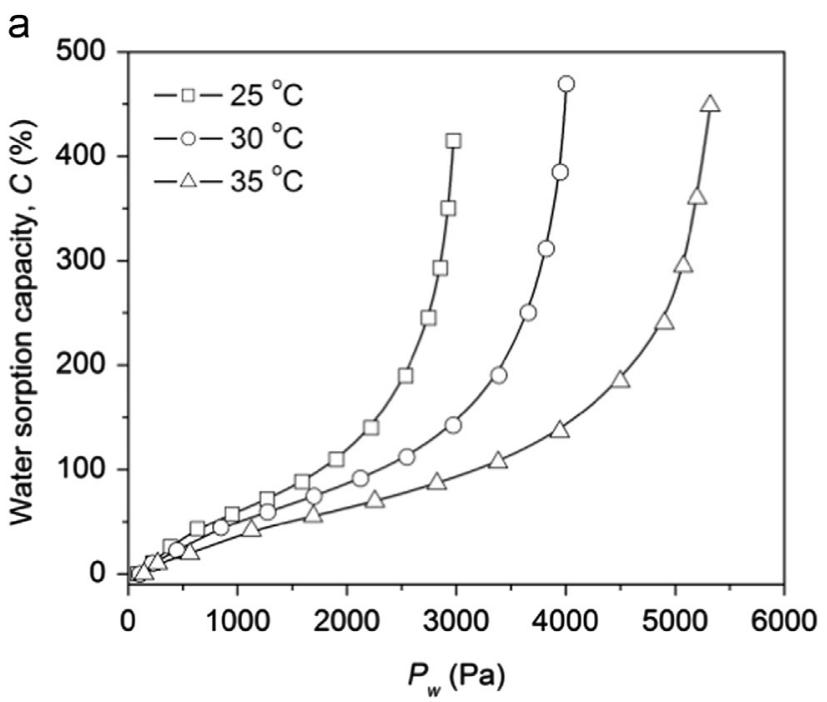

b
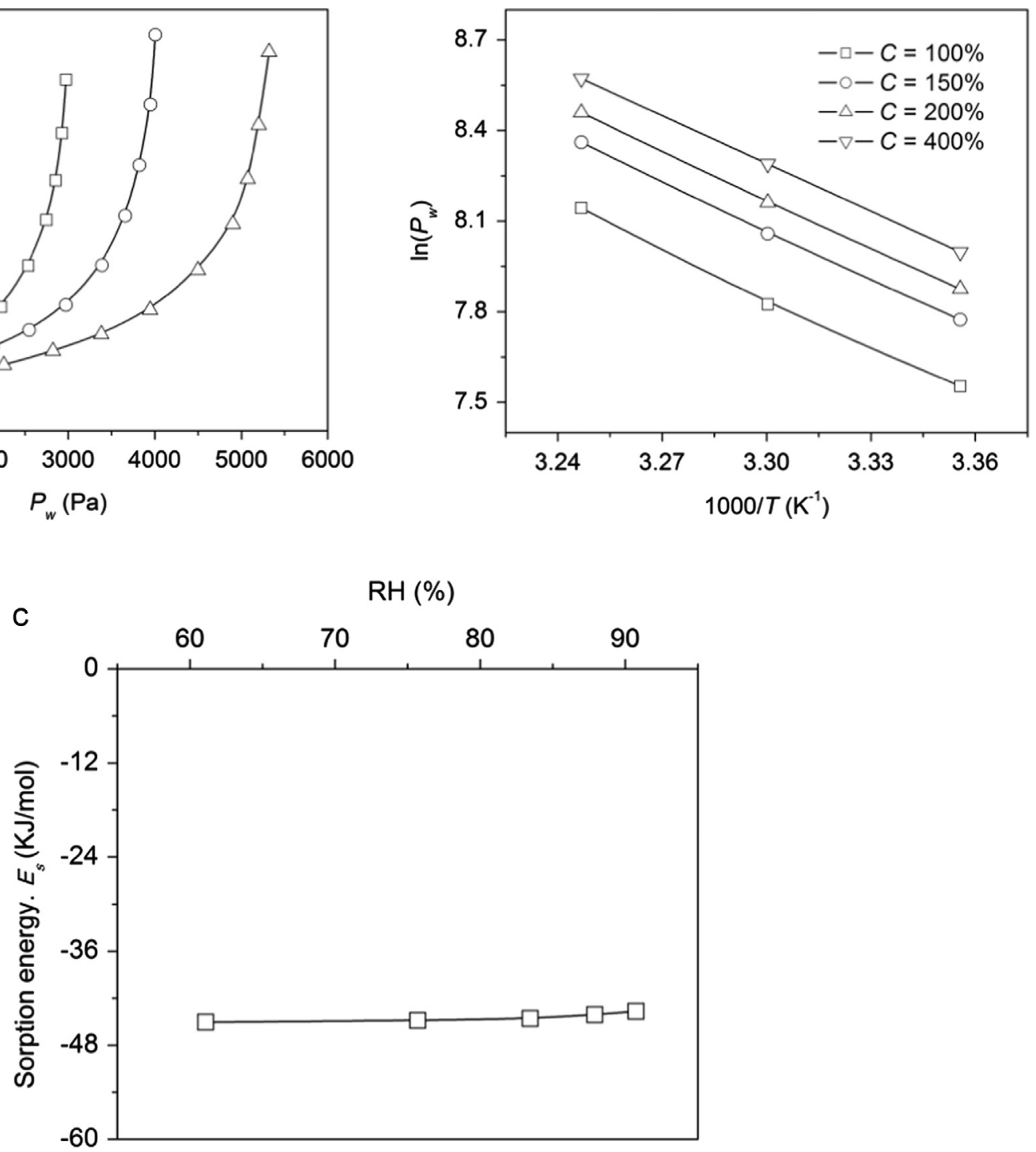

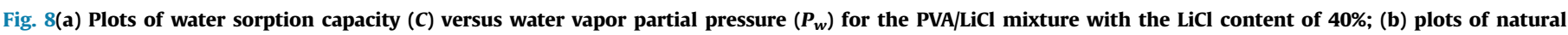

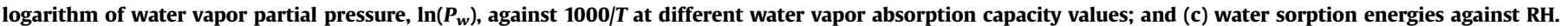

energies that are determined at $\mathrm{RH}$ of $70 \%$, the sorption energies at the sorption capacities corresponding to $\mathrm{RH}$ of $70 \%$ were determined and are displayed in Fig. 7. It is noteworthy that though the equilibrium sorption capacity of the PVA/LiCl mixture increased markedly with higher LiCl content (Fig. 5(b)), the energy released in the water sorption process changed marginally from around 40 to $50 \mathrm{~kJ} / \mathrm{mol}$.

Diffusion energies with different $\mathrm{LiCl}$ contents are calculated using Eq. (4) from the corresponding permeation activation energies and sorption energies and are shown in Fig. 7. It is observed that the diffusion energy barrier reduces by more than 3 times when the $\mathrm{LiCl}$ content changes from 0 to $50 \%$. Additionally, due to the fact that sorption energy varies within a small confined range, the decrease in permeation energy is largely due to the decrease in diffusion energy.

As far as low $\mathrm{LiCl}$ content membranes is concerned, at higher temperatures, the increase in diffusion rate dominates over the drop in sorption rate, resulting in higher water permeance. In contrast, the water vapor permeance of membranes with high $\mathrm{LiCl}$ contents decreases with higher temperature because the increase in diffusion rate is unable to compensate the decrease in absorption rate. As a result, higher water permeance is observed for membranes with higher $\mathrm{LiCl}$ content while operating at lower temperature. Because membranes with $\mathrm{LiCl}$ content higher than $50 \%$ are easily liquescent, they are physically unstable. As shown in Fig. 6(a), the membrane with a $\mathrm{LiCl}$ content of $50 \%$ has the highest water vapor permeance at temperatures below or equal to $40{ }^{\circ} \mathrm{C}$. This membrane is deemed to be highly suitable for dehumidifying air in tropical climates. However, for applications needing higher operating temperatures, membranes with $\mathrm{LiCl}$ content of around 33\% will have higher water permeance. These membranes provide consistent high moisture permeation for a wide range of temperature, because they have the permeation energy of zero.

\subsection{Dehumidification testing}

\subsubsection{Effect of LiCl content and feed air humidity}

The driving force for water vapor to permeate through the membrane is the difference in partial pressures between the feed and the permeate sides. Since the water vapor partial pressure of the feed air is low, at 27 mbar for the experimental condition, to obtain a significant level moisture of removal, the permeate pressure has to 
a

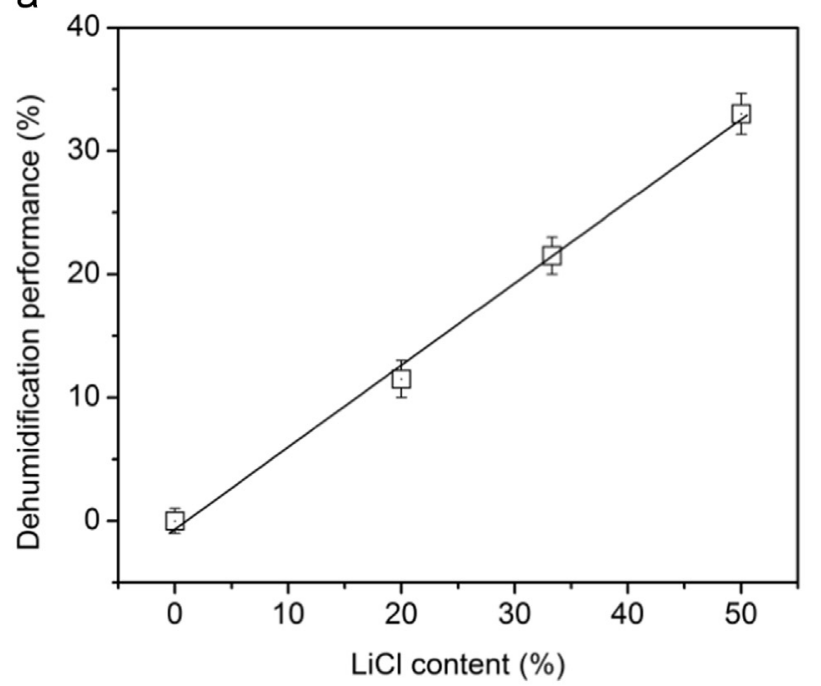

b

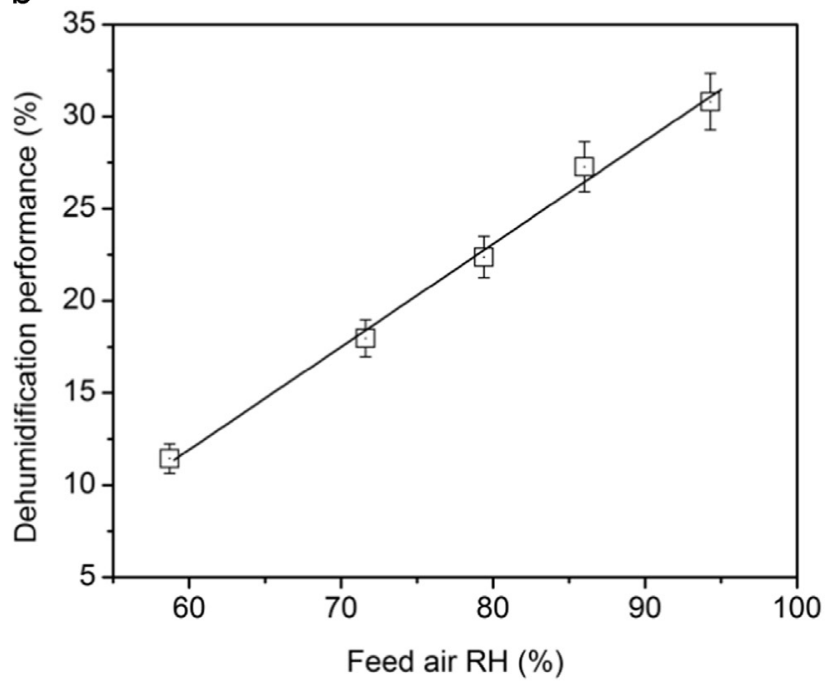

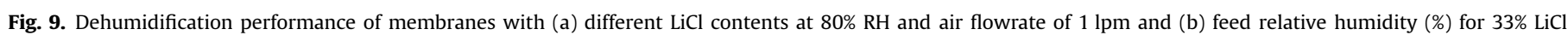
membrane.

a

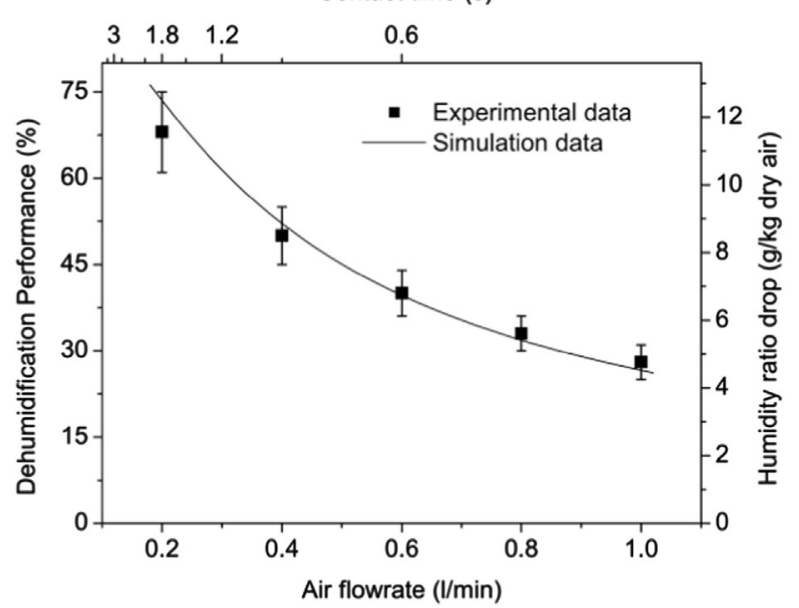

b

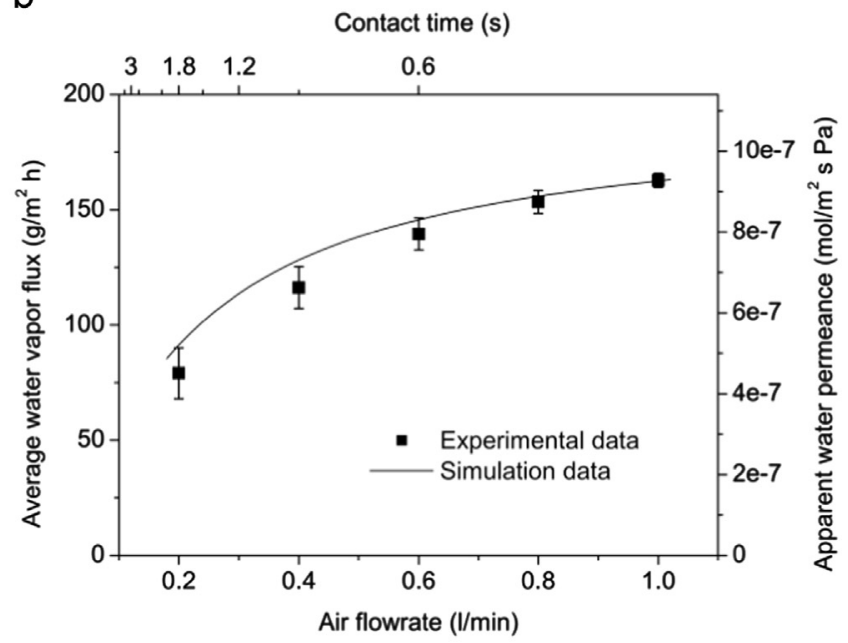

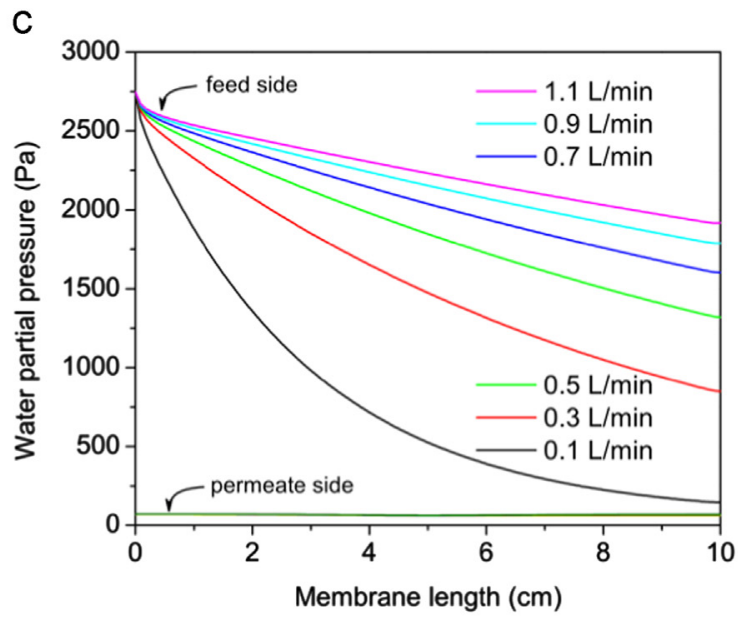

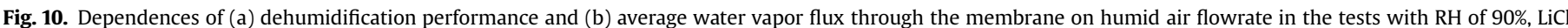

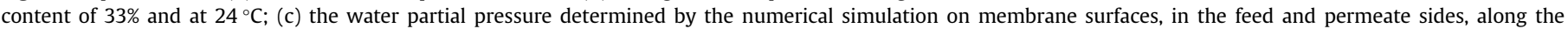
membrane length starting from input to output, at different feed air velocities. 
be below 27 mbar [12]. In our dehumidification tests, a permeate pressure of 1 mbar was employed.

The overall effect of $\mathrm{LiCl}$ content and feed air $\mathrm{RH}$ on the maximum moisture removal performance can be seen in Fig. 9. Generally, there is a linear increase in moisture removal performance at higher $\mathrm{LiCl}$ content. This is attributed to the increase in the water vapor permeation through the polymer as shown in Fig. 6 (a). Better dehumidification performance is also detected at higher feed $\mathrm{RH}$. This observation is attributed to the increasing water vapor permeance caused by a higher water vapor content shown in Fig. 5(a). This result indicates that the membrane performs better in high humidity condition such as in tropical climate.

\subsubsection{Effect of feed airflow rate}

Air flowrate is one of the key operating factors affecting the performance of membrane systems. Fig. 10(a) shows that the dehumidification performance of the membrane containing $33 \% \mathrm{LiCl}$ depreciates when air flow rate is higher. This is due to the shorter contact duration between the membrane and the feed air being treated. Similar observations are evidenced in the literature [25].

Unlike dehumidification performance, the flux of water vapor sieving through the membrane increases with higher air flowrate, as shown in Fig. 10(b). This is consistent with a reported result highlighting that increasing feed air flowrate leads to higher water vapor permeation [25]. Increased air flowrate leads to a thinner air boundary layer on the feed side of the membrane, resulting in a lower air resistance which favors the transport of water vapor. The other reason is that the partial water vapor pressure in the feed stream, and thus driving force for water vapor transmission, maintains at higher values when the air flowrate is increased as shown in Fig. 10(c).

From the average water vapor flux through the membrane, the apparent water vapor permeance was determined and is shown in the second $y$ axis on the right side of Fig. 10(b). The result indicates that the apparent water vapor permeance of the membrane in the working condition is smaller than the maximum water vapor permeance at the same temperature and $\mathrm{RH}$ conditions shown in Fig. 5(a). It means that the membrane is expected to achieve its maximum permeance only at very high air flowrates. However, at this high flowrate, its dehumidification performance is very low.

Thus far, it can be inferred from the results that there exists a trade-off between dehumidification performance with the water vapor removal rate when varying air flowrate. When a large change in humidity is desired, such as in the treatment of outdoor humid air before entering a room, low air flowrates are necessary to achieve effective dehumidification. When high water vapor removal rates are desired, such as during the treatment of humid air in a confined space, higher air flowrates are appropriate.

\section{Conclusion}

Hydrophilic composite PVA/LiCl membranes with $\mathrm{LiCl}$ content varying from 0 to $50 \%$ were fabricated on a flexible wire mesh support and low resistance intermediate $\mathrm{TiO}_{2}$ material. The developed membranes were thin, physically and chemically stable with a high degree of water vapor permeance and selectivity. The addition of $\mathrm{LiCl}$ improves both water sorption rate and diffusion rate, resulting in high water vapor permeation. As $\mathrm{LiCl}$ content increases from 0 to $50 \%$, the water vapor permeation energy changes from positive to negative values due to the large drop (more than 3 times) in diffusion energy barrier. The dehumidification performance of the membrane was also studied under different inlet air conditions. There exists an apparent trade-off between dehumidification performance and water vapor removal rate, as a result, the operation feed air flowrate should be judiciously selected based on practical needs.

\section{Acknowledgments}

The authors gratefully acknowledge the financial support provided by both Agency for Science, Technology and Research (A*Star) and Ministry of National Development - Singapore (MND) through their Green Building Joint Grant (No. 112176 0023) and National Research Foundation Competitive Research Programme NRF2011NRF_CRP003_003.

\section{References}

[1] J. Woods, Membrane processes for heating, ventilation, and air conditioning, Renew. Sustain. Energy Rev. 33 (2014) 290-304, http://dx.doi.org/10.1016/j. rser.2014.01.092.

[2] B. Yang, W. Yuan, F. Gao, B. Guo, A review of membrane-based air dehumidification, Indoor Built Environ. 24 (2013) 11-26, http://dx.doi.org/10.1177/ 1420326 X13500294.

[3] H. Sijbesma, K. Nymeijer, R. van Marwijk, R. Heijboer, J. Potreck, M. Wessling Flue gas dehydration using polymer membranes, J. Membr. Sci. 313 (2008) 263-276, http://dx.doi.org/10.1016/j.memsci.2008.01.024.

[4] S.R. Reijerkerk, R. Jordana, K. Nijmeijer, M. Wessling, Highly hydrophilic, rubbery membranes for $\mathrm{CO}_{2}$ capture and dehydration of flue gas, Int. J. Greenh. Gas Control 5 (2011) 26-36, http://dx.doi.org/10.1016/j.ijggc.2010.06.014.

[5] S.H. Yun, P.G. Ingole, K.H. Kim, W.K. Choi, J.H. Kim, H.K. Lee, Properties and performances of polymer composite membranes correlated with monomer and polydopamine for flue gas dehydration by water vapor permeation, Chem. Eng. J. 258 (2014) 348-356, http://dx.doi.org/10.1016/j.cej.2014.07.038.

[6] H. Lin, S.M. Thompson, A. Serbanescu-Martin, J.G. Wijmans, K.D. Amo, Ka Lokhandwala, et al., Dehydration of natural gas using membranes. Part I: Composite membranes, J. Membr. Sci. 413-414 (2012) 70-81, http://dx.doi. org/10.1016/j.memsci.2012.04.009.

[7] J.R. Du, L. Liu, A. Chakma, X. Feng, Using poly(N,N-dimethylaminoethyl methacrylate)/polyacrylonitrile composite membranes for gas dehydration and humidification, Chem. Eng. Sci. 65 (2010) 4372-4381, http://dx.doi.org/ 10.1016/j.ces.2010.05.005.

[8] Q. Cheng, F. Pan, B. Chen, Z. Jiang, Preparation and dehumidification performance of composite membrane with PVA/gelatin-silica hybrid skin layer, J. Membr. Sci. 363 (2010) 316-325, http://dx.doi.org/10.1016/j. memsci.2010.07.056.

[9] B. Bolto, M. Hoang, Z. Xie, A review of water recovery by vapour permeation through membranes, Water Res. 46 (2012) 259-266, http://dx.doi.org/10.1016/ j.watres.2011.10.052.

[10] G.M. Li, C. Feng, J.F. Li, J.Z. Liu, Y.L. Wu, Water vapor permeation and compressed air dehydration performances of modified polyimide membrane, Sep. Purif. Technol. 60 (2008) 330-334, http://dx.doi.org/10.1016/j. seppur.2007.05.007.

[11] P. Scovazzo, A.J. Scovazzo, Isothermal dehumidification or gas drying using vacuum sweep dehumidification, Appl. Therm. Eng. 50 (2013) 225-233, http: //dx.doi.org/10.1016/j.applthermaleng.2012.05.019.

[12] T.D. Bui, F. Chen, A. Nida, K.J. Chua, K.C. Ng, Experimental and modeling analysis of membrane-based air dehumidification, Sep. Purif. Technol. 144 (2015) 114-122, http://dx.doi.org/10.1016/j.seppur.2015.02.019.

[13] R. Xing, Y. Rao, W. TeGrotenhuis, N. Canfield, F. Zheng, D.W. Winiarski, et al., Advanced thin zeolite/metal flat sheet membrane for energy efficient air dehumidification and conditioning, Chem. Eng. Sci. 104 (2013) 596-609, http: //dx.doi.org/10.1016/j.ces.2013.08.061.

[14] A. Ito, Dehumidification of air by a hygroscopic liquid membrane supported on surface of a hydrophobic microporous membrane, J. Membr. Sci. 175 (2000) 35-42, http://dx.doi.org/10.1016/S0376-7388(00)00404-X.

[15] H.T. El-Dessouky, H.M. Ettouney, W. Bouhamra, A novel air conditioning system, Chem. Eng. Res. Des. 78 (2000) 999-1009, http://dx.doi.org/10.1205/ 026387600528111.

[16] L. Zhang, Fabrication of a lithium chloride solution based composite supported liquid membrane and its moisture permeation analysis, J. Membr. Sci. 276 (2006) 91-100, http://dx.doi.org/10.1016/j.memsci.2005.09.035.

[17] S.J. Metz, W.J.C. Van De Ven, M.H.V. Mulder, M. Wessling, Mixed gas water vapor/ $\mathrm{N}_{2}$ transport in poly(ethylene oxide) poly(butylene terephthalate) block copolymers, J. Membr. Sci. 266 (2005) 51-61, http://dx.doi.org/10.1016/j. memsci.2005.05.010.

[18] G.Q. Chen, C.A. Scholes, G.G. Qiao, S.E. Kentish, Water vapor permeation in polyimide membranes, J. Membr. Sci. 379 (2011) 479-487, http://dx.doi.org/ 10.1016/j.memsci.2011.06.023.

[19] L.Z. Zhang, Y.Y. Wang, C.L. Wang, H. Xiang, Synthesis and characterization of a $\mathrm{PVA} / \mathrm{LiCl}$ blend membrane for air dehumidification, J. Membr. Sci. 308 (2008) 198-206, http://dx.doi.org/10.1016/j.memsci.2007.09.056.

[20] J. Li, A. Ito, Dehumidification and humidification of air by surface-soaked liquid membrane module with triethylene glycol, J. Membr. Sci. 325 (2008) 
1007-1012, http://dx.doi.org/10.1016/j.memsci.2008.09.034.

[21] P. Scovazzo, Testing and evaluation of room temperature ionic liquid (RTIL) membranes for gas dehumidification, J. Membr. Sci. 355 (2010) 7-17, http: //dx.doi.org/10.1016/j.memsci.2010.02.067.

[22] F.F. Krull, C. Fritzmann, T. Melin, Liquid membranes for gas/vapor separations, J. Membr. Sci. 325 (2008) 509-519, http://dx.doi.org/10.1016/j. memsci.2008.09.018.

[23] F. Pan, H. Jia, Z. Jiang, X. Zheng, Enhanced dehumidification performance of PVA membranes by tuning the water state through incorporating organophosphorus acid, J. Membr. Sci. 325 (2008) 727-734, http://dx.doi.org/ 10.1016/j.memsci.2008.08.049.

[24] Y. Li, H. Jia, F. Pan, Z. Jiang, Q. Cheng, Enhanced anti-swelling property and dehumidification performance by sodium alginate-poly(vinyl alcohol)/polysulfone composite hollow fiber membranes, J. Membr. Sci. 407-408 (2012) 211-220, http://dx.doi.org/10.1016/j.memsci.2012.03.049.

[25] S. Roy, C.M. Hussain, S. Mitra, Poly(acrylamide-co-acrylic acid) hydrophilization of porous polypropylene membrane for dehumidification, Sep. Purif. Technol. 107 (2013) 54-60, http://dx.doi.org/10.1016/j.seppur.2012.12.014.

[26] S.J. Metz, N.F.A. Van Der Vegt, M.H.V. Mulder, M. Wessling, Thermodynamics of water vapor sorption in poly (ethylene oxide) poly (butylene terephthalate) block copolymers, Society (2003) 13629-13635.
[27] J.G. Wijmans, R.W. Baker, The solution-diffusion model: a review, J. Membr. Sci. 107 (1995) 1-21, http://dx.doi.org/10.1016/0376-7388(95)00102-I.

[28] N. Alghezawi, O. Şanli, L. Aras, G. Asman, Separation of acetic acid-water mixtures through acrylonitrile grafted poly(vinyl alcohol) membranes by pervaporation, Chem. Eng. Process. Process Intensif. 44 (2005) 51-58, http: //dx.doi.org/10.1016/j.cep.2004.03.007.

[29] D.J. Upadhyay, N.V. Bhat, Separation of azeotropic mixture using modified PVA membrane, J. Membr. Sci. 255 (2005) 181-186, http://dx.doi.org/10.1016/j. memsci.2005.01.033.

[30] S. Liu, F. Wang, T. Chen, Synthesis of poly(ether ether ketone)s with high content of sodium sulfonate groups as gas dehumidification membrane materials, Macromol. Rapid Commun. 22 (2001) 579-582, http://dx.doi.org/ 10.1002/1521-3927(20010501)22:8 < 579::AID-MARC579 > 3.0.CO;2-4.

[31] F. Müller-Plathe, Diffusion of water in swollen poly(vinyl alcohol) membranes studied by molecular dynamics simulation, J. Membr. Sci. 141 (1998) 147-154, http://dx.doi.org/10.1016/S0376-7388(97)00289-5.

[32] C. Pérez-Alonso, C.I. Beristain, C. Lobato-Calleros, M.E. Rodríguez-Huezo, E. J. Vernon-Carter, Thermodynamic analysis of the sorption isotherms of pure and blended carbohydrate polymers, J. Food Eng. 77 (2006) 753-760, http: //dx.doi.org/10.1016/j.jfoodeng.2005.08.002. 